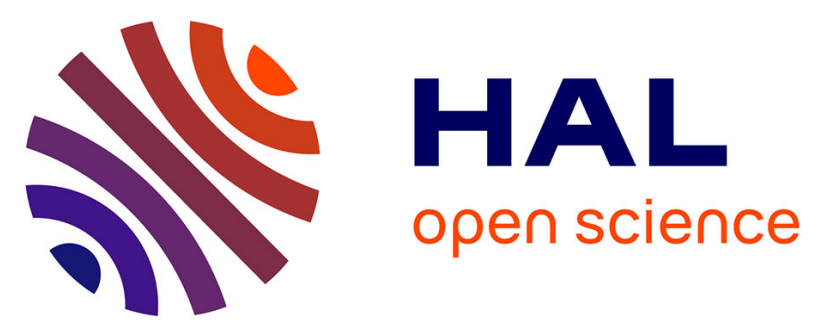

\title{
Pegylated liposomal doxorubicin, 5-fluorouracil and cisplatin versus mitomycin-C, 5 -fluorouracil and cisplatin for advanced gastric cancer: a randomized phase II trial
}

Stefano Cascinu, Eva Galizia, Roberto Labianca, Francesco Ferraù, Francesca Pucci, Rosa Rita Silva, Gabriele Luppi, Giordano Domenico Beretta, Rossana Berardi, Mario Scartozzi

\section{To cite this version:}

Stefano Cascinu, Eva Galizia, Roberto Labianca, Francesco Ferraù, Francesca Pucci, et al.. Pegylated liposomal doxorubicin, 5-fluorouracil and cisplatin versus mitomycin-C, 5-fluorouracil and cisplatin for advanced gastric cancer: a randomized phase II trial. Cancer Chemotherapy and Pharmacology, 2010, 68 (1), pp.37-43. 10.1007/s00280-010-1424-8 . hal-00619931

\section{HAL Id: hal-00619931 \\ https://hal.science/hal-00619931}

Submitted on 7 Sep 2011

HAL is a multi-disciplinary open access archive for the deposit and dissemination of scientific research documents, whether they are published or not. The documents may come from teaching and research institutions in France or abroad, or from public or private research centers.
L'archive ouverte pluridisciplinaire HAL, est destinée au dépôt et à la diffusion de documents scientifiques de niveau recherche, publiés ou non, émanant des établissements d'enseignement et de recherche français ou étrangers, des laboratoires publics ou privés. 
TITLE: PEGYLATED LIPOSOMAL DOXORUBICIN， 5-FLUOROURACIL AND CISPLATIN VERSUS MITOMYCIN-C, 5-FLUOROURACIL AND CISPLATIN FOR ADVANCED GASTRIC CANCER: A RANDOMIZED PHASE II TRIAL.

Cascinu $\mathrm{S}^{1}$, Galizia $\mathrm{E}^{2}$, Labianca $\mathrm{R}^{3}$, Ferraù $\mathrm{F}^{4}$, Pucci $^{5}$, Silva $\mathrm{RR}^{2}$, Luppi $\mathrm{G}^{6}$, Beretta $\mathrm{GD}^{7}$, Berardi $\mathrm{R}^{1}$, Scartozzi $\mathrm{M}^{1}$.

${ }^{1}$ Clinica di Oncologia Medica, Azienda Ospedaliera Ospedali Riuniti, Università Politecnica delle Marche, Ancona, Italy; ${ }^{2}$ Oncologia Medica, Ospedale “E. Profili”, Fabriano, Italy; ${ }^{3}$ Oncologia Medica, Ospedali Riuniti Bergamo, Italy; "Oncologia Medica, Ospedale "San Vincenzo", Taormina, Italy; ${ }^{5}$ Oncologia Medica, Azienda Ospedaliero-Universitaria, Parma, Italy; ${ }^{6}$ U.O. di Oncologia e di Radiologia I^, Policlinico, Modena, Italy; ${ }^{7}$ U.O. Oncologia Ospedale “Sant’Orsola Fatebenefratelli”, Brescia, Italy.

\section{Correspondence to:}

Stefano Cascinu, MD

Clinica di Oncologia Medica, AO Ospedali Riuniti, Università Politecnica delle Marche Via Conca, 60020, Ancona

ITALY

Phone: +390715964169

Fax: +390715964192

e-mail: cascinu@yahoo.com 


\section{SUMMARY}

Purpose: Clinical data suggested that a regimen incorporating doxorubicin to 5-fluorouracil (5-FU) and cisplatin may be more effective but probably quite toxic for advanced gastric cancer patients. With the aim to maintain efficacy while reducing toxicity, we compared the activity and safety of a combination of 5-FU, cisplatin and pegylated liposomal doxorubicin with a combination of 5-FU, cisplatin and mitomycin-C.

Patients and methods: Seventy-eight patients were randomised to receive $5-\mathrm{FU}\left(400 \mathrm{mg} / \mathrm{m}^{2}\right.$ bolus, $600 \mathrm{mg} / \mathrm{m}^{2} 22 \mathrm{~h}$ continuous infusion day 1 and 2$)$ and cisplatin $\left(50 \mathrm{mg} / \mathrm{m}^{2}\right.$ day 1$)$ every 2 weeks, combined either with pegylated liposomal doxorubicin $\left(20 \mathrm{mg} / \mathrm{m}^{2}\right.$ day 1 every two weeks) (arm A) or mitomycin-C (7 mg/m² every 6 weeks) (arm B).

Results: The overall response rate was $64.1 \%$ in arm A and $38.5 \%$ in arm B (p=0.041). The median time to tumour progression and overall survival were 7.93 and 5.14 months $(\mathrm{p}=0.04)$ and 12.1 and 8.3 months $(\mathrm{p}=0.02)$ in arm $\mathrm{A}$ and $\mathrm{B}$ respectively. Fourteen patients in arm A and 18 patients in arm B experienced a grade $3 / 4$ toxic effect.

Conclusions: A combination of pegylated liposomal doxorubicin, cisplatin and 5-FU can be safely administered in gastric cancer patients with a promising efficacy profile.

Keywords: advanced gastric cancer; pegylated liposomal doxorubicin; metastatic gastric cancer; cisplatin-5FU-containing regimen. 


\section{INTRODUCTION}

Prognosis for advanced, not operable gastric cancer patients is still disappointing, with systemic chemotherapy representing the only effective option. Moreover, in spite of the large number of chemotherapy regimens assessed in several randomised trials, still there is not an internationally accepted standard of care.

In most countries, a combination regimen containing 5-fluorouracil (5-FU) and cisplatin is considered a standard of care and a reference regimen in randomised trials. Moreover, clinical data from randomised studies and a meta-analysis suggested that a regimen incorporating a third drug, other than 5-FU and cisplatin, may be more effective [1-3].

According to this finding, previous data from clinical studies showed that a regimen consisting of epirubicin, 5-FU and cisplatin (ECF) may result in improved survival in metastatic gastric cancer and, for the first time, in the peri-operative setting [1,4].

Nevertheless, the use of an anthracycline containing combination has been often regarded as controversial, without a general agreement for the clinical practice. Most of these uncertainties are due to the toxicity profile of a three-drug combination.

The incorporation of docetaxel to 5-FU/cisplatin chemotherapy (TCF) showed interesting results, in terms of activity and efficacy, but some problems related to the toxicity profile arisen, questioning once again the opportunity to increase the intensity of treatment in gastric cancer [2].

Globally, the survival advantage deriving from the use of a three-drug combination seemed similar to the difference in survival observed between combination and single-agent chemotherapy, thus supporting the opportunity to continue to explore more effective combination regimens [3].

Alternatively, mitomycin-C has been proved effective in advanced gastric cancer, with an acceptable toxicity [5].

In a previous study, we demonstrated that the combination of mitomycin- $\mathrm{C}$, cisplatin and 5-FU should be considered a well tolerated and effective palliative chemotherapeutic regimen, with a $46 \%$ response rate and a median survival of 11 months [5]. However, the use of mitomycin-C has 
been progressively abandoned during the years, along with the introduction of anthracycline- and docetaxel-based triplets.

In a prospective randomized study by Ross at al, previously untreated patients with advanced gastric cancer were assigned to receive either ECF or MCF. The two regimens showed the same efficacy (overall response rate $42.4 \%$ vs $44.1 \%$ respectively). Interestingly, QoL scores resulted better with ECF; however, ECF resulted in more grade 3-4 neutropenia and grade 2 alopecia. [6] The development of alternative formulations of anthracyclines, such as pegylated liposomal doxorubicin, with lower inherent toxicity, may improve tolerability and efficacy of anthracyclinebased regimens.

The efficacy and the favourable toxicity profile were demonstrated in different tumour types [7-9]:

There is no previous phase I/dose-finding study testing the combination of pegylated liposomal doxorubicin, cis platin and 5-FU; however, Eng et al conducted a phase I trial showing that the combination of pegylated liposomal doxorubicin (doses $20 \mathrm{mg} / \mathrm{m}^{2}$ or 30

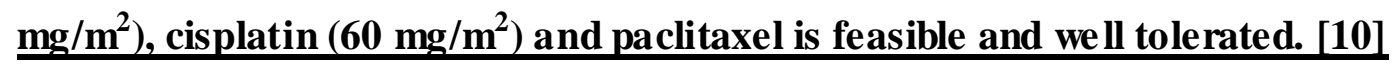

In gastric cancer, a regimen of pegylated liposomal doxorubicin, infusional 5-FU and mitomycin-C, yielded a promising overall response rate $(47 \%)$, with an interesting overall survival and median time to progression (14.7 and 8.4 months respectively) [11].

The REAL-2 trial showed that oxaliplatin and capecitabine may substitute for cisplatin and 5-FU respectively, without decreasing efficacy and with improved favourable safety. Given the better cardiac safety profile and the slightly lower incidence of alopecia of pegylated liposomal doxorubicin over anthracyclines, we try to assess the activity and safety of a combination of pegylated liposomal doxorubicin, 5-FU and cisplatin in a phase II randomised trial, with the three drugs combination of mitomycin-C, 5-FU and cisplatin as the comparative arm [12]. 


\section{PATIENTS AND METHODS}

This multicenter, randomized, phase II study was approved by the local Ethics Committees and performed according to the Good Clinical Practice (GCP). Randomisation was done centrally by a central data management, with the random sequence previously generated by a computer programme in a 1:1 ratio, involving stratification by institution, disease extent, and performance status.

\section{Eligibility}

Patients were included in the study according to the following eligibility criteria: pathologically confirmed locally advanced non-resectable or metastatic gastric cancer; measurable or assessable lesions; age 75 years or younger; Eastern Cooperative Oncology Group (ECOG) performance status of 2 or less; no prior chemotherapy (adjuvant chemotherapy was allowed if performed more than 12 months prior to enrolment); adequate bone marrow (leukocytes $\geq 3,000 / \mu \mathrm{L}$ and thrombocytes $\geq 100,000 / \mu \mathrm{L}$ ), cardiac (cardiac ejection fraction within normal limits), renal (creatinine clearance $\geq 60 \mathrm{~mL} / \mathrm{min}$ ) and liver (bilirubin $\leq 1.5 \mathrm{mg} / \mathrm{dL}$ ) function; contraception was required for females with reproductive potential. Excluding criteria were: previous chemotherapy for advanced disease, second malignancy, uncontrolled infection, symptomatic CNS metastases, concomitant radiation therapy, other concomitant therapies aiming at tumour reduction, and life expectancy of less than 3 months.

No prior chemotherapy, except for adjuvant chemotherapy that had been completed more than 6 months before registration, and no radiotherapy within 4 weeks before study registration were allowed. Target lesions in previously irradiated areas were not allowed.

Written informed consent was obtained from all participants after the nature of the study had been fully explained. 


\section{Treatment plan}

Patients were randomly assigned to receive 5 -FU $\left(400 \mathrm{mg} / \mathrm{m}^{2}\right.$ bolus, followed by $600 \mathrm{mg} / \mathrm{m}^{2} 22 \mathrm{~h}$ continuous infusion day 1 and 2$)$ and cisplatin $\left(50 \mathrm{mg} / \mathrm{m}^{2}\right.$ day 1$)$ every 2 weeks, combined either with pegylated liposomal doxorubicin $\left(20 \mathrm{mg} / \mathrm{m}^{2}\right.$ day 1 every two weeks) (LdCF, arm A) or mitomycin-C (7 mg/m² every 6 weeks) (MCF, arm B).

Chemotherapy was administered until tumour progression, intolerable side effects or patient's refusal. Assessment of tumour-related symptoms was performed every 3 weeks. Evaluation of side effects took place on a weekly basis.

The prophylactic use of hematopoietic growth factors was not allowed during treatment, except for patients with febrile neutropaenia or grade 4 myelosuppression at the investigators' discretion.

\section{Evaluation of toxicity and response}

Assessments before and during treatment consisted of a complete medical history and physical examination; laboratory tests, including haematological and biochemical tests; CT of the abdomen or MRI when clinically indicated. Chest X-rays were requested as minimal chest assessment; chest CT was preferred and performed whenever possible. As a result, in more than $80 \%$ of the included cases, staging procedures included a CT scan of the chest. Gastroscopy were planned only if clinically indicated.

Moreover, the baseline evaluation included assessment of ECOG performance status in order to assess how the disease affected the daily living abilities; pain was tracked by VAS scale.

Chemotherapy toxicity was assessed every 2 weeks and was recorded according to the National Cancer Institute Common Toxicity Criteria grade (NCI-CTC version 2.0).

Dose modifications of chemotherapeutic agents were based on absolute neutrophil counts (ANC) and platelet counts. Chemotherapy was delayed until recovery if neutrophilis decreased to < $1500 / \mu \mathrm{L}$ or the platelet count decreased to $<100.000 / \mu \mathrm{L}$. 
A $25 \%$ dose reduction of chemotherapeutic drugs was mandatory in case of grade 4 neutropenia, grade 3-4 thrombocytopenia, grade 2-3 mucositis, diarrhoea or hand-foot syndrome. Treatment was stopped in case of grade 4 mucositis, diarrhoea, or hand-foot syndrome. In the presence of other grade 4 NCI-CTC toxicities, patients should be withdrawn from the study.

Response Evaluation Criteria in Solid Tumors (RECIST 1.0 version) was used for defining response and was performed every 9 weeks and during follow-up visits; patients were assessed with the same imaging methods used at the beginning of the study (unless the patient discontinued treatment for disease progression) by the same investigator. Tumour response was assessed by an ind ependent radiologist as central reviewer.

Histologic confirmation at endoscopy was required to determine a complete response at the primary site.

Peritoneal carcinomatosis was defined as measurable disease if patients presented with at least one peritoneal nodule $>2 \mathrm{~cm}$ at conventional CT scan, otherwise it was defined as not measurable disease.

Patients who received at least one cycle of treatment were considered assessable for response and toxicity in an intention-to-treat analysis.

\section{Statistical Considerations}

The primary endpoints were to compare objective response (OR), defined as the proportion of patients whose best response was either partial response (PR) or complete response (CR) and toxicity between the two treatment arms.

An optimal two-stage Simon design [13] was used to determine the number of patients needed to be accrued in the experimental arm (LdCF: arm A). The control arm (MCF: arm B) served as internal control arm to a void selection bias and did not influence this calculation.

It was estimated that a response rate $>25 \%$ would justify continuing the trial ( $\mathrm{H} 0)$. The response rate was expected to be $45 \%(\mathrm{H} 1)$. 
Given the good results obtained with the use of anthracyclines, cisplatin and 5-FU combinations, we could expect that the experimental arm was more effective (or at least equally effective) than the reference arm.

With a type I error of 5\%, one-sided, and a power of $80 \%$, the required number of patients was 38 . Therefore, the total number of patients to be randomised was at least 76 . A $10 \%$ dropout was accounted for in the sample-size calculation. If more than the planned 76 patients were eligible in the enrolment-time window at the different centres at the time that enrolment was stopped, the Italian Ministry of Health gave authorisation for these additional patients to be included in the study.

Secondary endpoints included time to progression (TTP) and overall survival (OS). TTP was defined as the interval between randomisation and date of progression, last follow-up visit, or death from any cause, and OS was defined as the interval between randomisation and last follow-up visit or death from any cause, where deaths were considered events.

Event-time distributions were estimated by the Kaplan-Meier method and compared using the logrank test. All randomised patients who met the eligibility criteria were included in the efficacy analysis of their allocated group, whereas the analysis of toxic effects was restricted to patients who actually received at least one cycle of treatment. Because the study is a phase II trial and not a phase III trial, all comparisons only have an explorative value. Analyses were carried out using MedCalc software (version 10.4.0). 


\section{RESULTS}

Between March 2002 and March 2005, seventy-eight patients from 8 Italian Centres were randomized to receive LdCF or MCF. Patients characteristics resulted well balanced between the treatment groups and are listed in Table 1. Despite the fact there were more G3 tumours and more patients with ECOG PS2 in group B, these differences were not statistically significant.

Most of the patients had metastatic gastric adenocarcinoma.

\section{Treatment efficacy}

Seventy-seven of 78 patients were assessable for response; one patient in arm B was not assessable but was included in the intent-to-treat analysis and kept in the denominator of the response rate.

Globally, 280 cycles of LdCF (arm A) and 286 cycles of MCF ( $\operatorname{arm~B)}$ were administered; The median number of cycles was 6 (range 2-10) in arm A and 6 (range 1-13) in arm B.

Toxicity-induced treatment delays and dose reductions had to be performed respectively in 12 (30.8\%) and 9 patients (23\%) in arm A and in $12(30.8 \%)$ and 8 patients (20\%) in arm B.

Detailed data related to response rate are reported in table 2. The overall response rate (ORR) for patients in arm A (complete response [CR] + partial response [PR]) was 64.1\%; 95\% CI: 48-77), whereas ORR for patients in group B was 38.5\% (95\% CI 24-54). Objective response was thus significantly higher in the liposomal doxorubicin group by $25.6 \%$ (95\% CI 1.67 to $46.67 ; \chi^{2}$ test= 4.14; $\mathrm{p}=0.041)$.

The median time to tumour progression (TTP) for patients in group A and B was respectively 7.93 and 5.14 months (HR 0.62, 95\% CI 0.37-0.97, $\mathrm{p}=0.04$ ) (figure 1). The overall survival was 12.1 months for patients in group A and 8.3 months for patients in group B (HR 0.59, 95\% CI 0.34-0.94, $\mathrm{p}=0.02$ ) (figure 2).

Fourteen patients (35.9\%) in arm A and 19 patients (48.7\%) in arm B had tumour-related symptoms before therapy. Twenty-six patients in arm A (66.7\%) and 23 patients in arm B (59\%) showed an improvement in at least one of their symptoms without worsening of any other symptom. 


\section{Toxicity}

Table 3 summarises the clinically relevant adverse events: 14 patients in arm A and 21 patients in arm B had a grade 3 or 4 toxic effects. The most commonly reported adverse event of grade 3-4 was neutropenia in both groups. There were no toxic deaths

There was no statistically significant differe nce in terms of grade $3+4$ toxicity between the two groups. However, considering the global grade 3-4 hematologic toxicity (neutropenia + $\underline{\text { thrombocytopenia }+ \text { febrile neutropenia }+ \text { anemia) we found a statistically significant }}$ difference between the two groups (LdCF 25.6\% vs MCF 56.4\%, p 0.011). 


\section{DISCUSSION}

Although available data seem to suggest a small benefit for the use of a three-drug anthracyclinescontaining chemotherapy regimen, it is still unclear whether this small benefit should be considered outweighed by a worsening in the toxicity profile in the palliative setting [3]. Consequently, the incorporation of anthracyclines into a cisplatin-5FU-containing regimen for advanced gastric cancer is still matter of scientific debate, as clinical findings on this topic cannot be considered definitive.

An interesting three-drug combination was tested by Felici et al in a phase II trial in which a biweekly regimen containing cisplatin, epirubicin and infusional 5-FU (as de Gramont schedule) was administered in 52 patients with previously untreated, locally advanced or metastatic gastric cancer. The Authors observed an overall response rate of $34.6 \%$, with grade 3 or 4 neutropenia observed in $44 \%$ of patients, thrombocytopenia in $6.7 \%$ and mucositis in $11.9 \%$. [13]

The use of liposomal doxorubicin seems to possess the necessary potential for maintaining the adequate efficacy without increasing toxicity.

In our study, the incorporation of liposomal doxorubicin in a three-drug combination, including cisplatin and 5-FU (LdCF) determined interesting results in terms of response rate (64\% vs 38.5\% the wide confidence intervals of the difference in objective response rate among the two arms (25.6\%, 95\%CI 1.67-46.67) could be attributed to the relatively high difference in RR observed for the 2 treatment arms and the relatively small sample size), time to tumour progression ( 7.9 months) and median survival time (12.1 months). These data compare well with those observed with ECF or TCF but with a more favourable toxicity profile [1,2].

It is worthy to note that the median TTP and OS in this phase II study are similar to those reported in the REAL-2 study, but the response rate is considerably higher than with any of the epirubicinbased triplets. However, we must underline that REAL-2 is a phase III trial, whereas our trial is a randomized phase II one and could overestimate the obtained results in comparison to a randomized phase III trial." 
In our study, Grade 3/4 hand\&foot syndrome and mucositis were more common in patients who received pegylated doxorubicin, however they were easily manageable and did not have any impact on treatment administration.

Patients characteristics resulted well balanced between the treatment groups, despite the fact there were some difference in terms of grading and stage of tumours and performance status: there were more patients with G3 and locally advanced gastric cancer and more patients with ECOG PS2 in group B, however the differences were not statistically significant.

It should be noted that in the present study, the control arm showed worse efficacy than the previous study with the same regimen [6]. It should be taken into account that a phase II trial could overestimate the obtained results in comparison to a randomized phase II trial.

New cytotoxic agents, such as irinotecan and taxanes, seem to represent a more appealing approach for the treatment of advanced gastric cancer. However, irinotecan cannot be combined safely with 5-FU and cisplatin, since the gastrointestinal toxicity represents a relevant problem for the majority of patients [14]. On the other hand, the use of docetaxel, although likely to increase efficacy, may raise substantial concerns in the clinical practice for the toxicity profile linked to its administration, suggesting a selected use for DCF in relatively young, good performance status patients, particularly when an improved response rate may lead to an improved chance of resection in locally advanced disease. For this reason, TCF is not widespread used in advanced gastric cancer [15].

Thuss-Patience et al conducted a randomized phase II trial in order to assess a combination of docetaxel and 5-FU (DF) in comparison to ECF. The Authors did not find significative difference in terms of response rate (DF 37.8\% and ECF 35.6\%) and overall survival (9.5 and 9.7 months respectively) between the two arms. Moreover, treatment delays and dose reductions were similar between DF and ECF arms. [16] It should be noted that patients in DF arms experienced more nausea\&vomiting, mucositis and neutropenia than patients in LdCF arm of our study.

One of the aim of future trials on new chemotherapeutic regimens in gastric cancer should be the pursuit of new way to combine effective drugs without increasing toxicity. Unfortunately, until now 
in advanced gastric cancer small survival benefit has been achieved at the expense of increased toxicity. In the palliative setting, this should be considered a major issue.

In the present trial, the predominant toxicities of LdCF were leukopenia and cutaneous toxicity, whereas the major toxicities of MCF were leukopenia and thrombocytopenia. Overall, the incidence of severe toxicity was low and in most cases it was not clinically relevant.

In conclusion, our data show that liposomal doxorubicin, cisplatin and 5-FU can be safely administered in combination and shows promising efficacy compared with a three-drugs regimen including mitomycin, cisplatin and 5-FU.

the median TTP and OS in this phase II study are similar to those reported in the REAL 2 study, but the response rate is considerably higher than with any of the epirubicin-based triplets.

Moreover, this combination may have a therapeutic activity, similar to more aggressive regimens or regimens including new and much more expensive drugs, with a lower and more easily manageable toxicity profile and, if results will be confirmed in larger trials, it may further expand the choice of active regimens in the clinical practice. 


\section{REFERENCES}

1. Webb A, Cunningham D, Scarffe JH, Harper P, Norman A, Joffe JK, Hughes M, Mansi J, Findlay M, Hill A, Oates J, Nicolson M, Hickish T, O'Brien M, Iveson T, Watson M, Underhill C, Wardley A, Meehan M (1997). Randomized trial comparing epirubicin, cisplatin, and fluorouracil versus fluorouracil, doxorubicin, and methotrexate in advanced esophagogastric cancer. J Clin Oncol; 15: 261-267.

2. Van Cutsem E, Moiseyenko VM, Tjulandin S, Majlis A, Constenla M, Boni C, Rodrigues A, Fodor M, Chao Y, Voznyi E, Risse ML, Ajani JA; V325 Study Group (2006). Phase III study of docetaxel and cisplatin plus fluorouracil compared with cisplatin and fluorouracil as first-line therapy for advanced gastric cancer: a report of the V325 Study Group. J Clin Oncol; 24: 4991-7.

3. Wagner AD, Grothe W, Haerting J, Kleber G, Grothey A, Fleig WE (2006). Chemotherapy in Advanced Gastric Cancer: A Systematic Review and Meta-Analysis Based on Aggregate Data. J Clin Oncol; 24: 2903-2909.

4. Cunningham D, Allum WH, Stenning SP, Thompson JN, Van de Velde CJ, Nicolson M, Scarffe JH, Lofts FJ, Falk SJ, Iveson TJ, Smith DB, Langley RE, Verma M, Weeden S, Chua YJ, MAGIC Trial Participants (2006). Perioperative chemotherapy versus surgery alone for resectable gastroesophageal cancer. N Engl J Med; 355: 11-20.

5. Cascinu S, Baldelli AM, Catalano V, Giordani P, Beretta GD, Silva RR, Gasparini G, Mari D, Maisano R, Salvagni S, Barni S, Labianca R, Frontini L, Curti C, Catalano G (2002). Infusional 5-fluorouracil, cisplatin and mitomycin $\mathrm{C}$ in advanced gastric cancer: $\mathrm{A}$ low cost effective regimen. Br J Cancer; 86: 213-217.

6. Ross P, Nicolson M, Cunningham D, Valle J, Seymour M, Harper P, Price T, Anderson H, Iveson T, Hickish T, Lofts F, Norman A (2002). Prospective randomized trial of comparing mitomycin, cisplatin, and protracted venous-infusion fluorouracil (PVI 5-FU) with 
epirubicin, cisplatin, and PVI 5-FU in advanced esophagogastric cancer. J Clin Oncol; 20: 1996-2004.

7. Sparano JA, Makhson AN, Semiglazov VF, Tjulandin SA, Balashova OI, Bondarenko IN, Bogdanova NV, Manikhas GM, Oliynychenko GP, Chatikhine VA, Zhuang SH, Xiu L, Yuan Z, Rackoff WR. Pegylated liposomal doxorubicin plus docetaxel significantly improves time to progression without additive cardiotoxicity compared with docetaxel monotherapy in patients with advanced breast cancer previously treated with neoadjuvantadjuvant anthracycline therapy: results from a randomized phase III study (2009). J Clin Oncol; 27:4522-9.

8. Bartlett NL, Niedzwiecki D, Johnson JL, Friedberg JW, Johnson KB, van Besien K, Zelenetz AD, Cheson BD, Canellos GP; Cancer Leukemia Group B (2007). Gemcitabine, vinorelbine, and pegylated liposomal doxorubicin (GVD), a salvage regimen in relapsed Hodgkin's lymphoma: CALGB 59804. Ann Oncol; 18: 1071-9.

9. Bookman MA, Brady MF, McGuire WP, Harper PG, Alberts DS, Friedlander M, Colombo N, Fowler JM, Argenta PA, De Geest K, Mutch DG, Burger RA, Swart AM, Trimble EL, Accario-Winslow C, Roth LM (2009). Evaluation of new platinum-based treatment regimens in advanced-stage ovarian cancer: a Phase III Trial of the Gynecologic Cancer Intergroup. J Clin Oncol; 27:1419-25.

10. Eng C, Mauer AM, Fleming GF, Bertucci D, Rotmensch J, Jacobs RH \& Ratain MJ (2001). Phase I study of pegylated liposomal doxorubicin paclitaxel, and cisplatin in patients with advanced solid tumors. Ann Oncol; 12: 1743-47.

11. Gnad-Vogt SU, Hofheinz RD, Saussele S, Kreil S, Willer A, Willeke F, Pilz L, Hehlmann R, Hochhaus A (2005). Pegylated liposomal doxorubicin and mitomycin C in combination with infusional 5-fluorouracil and sodium folinic acid in the treatment of advanced gastric cancer: results of a phase II trial. Anticancer Drugs; 16:435-40. 
12. Cunningham D, Starling N, Rao S, et al (2008). Capecitabine and oxaliplatin for advanced esophagogastric cancer. New Engl J Med; 358:36-46.

13. Felici A, Carlini P, Ruggeri EM, Gamucci T, Pollera CF, De Marco S, Fariello AM, Moscetti L, Gelibter A, Adami E, Sperduti I and Cognetti F (2006). Bi-weekly chemotherapy with cisplatin, epirubicin, folinic acid and 5-fluororacil continuous infusion plus g-csf in advanced gastric cancer: a multicentric phase II study. Cancer Chemother Pharmacol; 57:59-64.

14. Simon R (1989). Optimal two-stage design for phase II clinical trials. Control Clin Trials; 10:1-10.

15. Scartozzi M, Galizia E, Verdecchia L, Berardi R, Antognoli S, Chiorrini S, Cascinu S (2007). Chemotherapy for advanced gastric cancer: across the years for a standard of care. Expert Opin Pharmacother; 8: 797-808.

16. Thuss-Patience PC, Kretzschmar A, Repp M, Kingreen D, Hennesser D, Micheel S, Pink D, Scholz C, Dörken B, Reichardt P (2005). Docetaxel and continuous-infusion fluorouracil versus epirubicin, cisplatin, and fluorouracil for advanced gastric adenocarcinoma: a randomized phase II study. J Clin Oncol; 23: 494-501. 
Table 1: Patients characteristics

\begin{tabular}{|c|c|c|c|}
\hline & Whole group & Group A $(\%)$ & Group B $(\%)$ \\
\hline NUMBER & 78 & $39(50)$ & $39(50)$ \\
\hline AGE (range) & $63(33-75)$ & $64(33-74)$ & $62(37-75)$ \\
\hline \multicolumn{4}{|l|}{ SEX } \\
\hline male & $50(64)$ & $27(69.2)$ & $23(59)$ \\
\hline female & $28(36)$ & $12(30.8)$ & $16(41)$ \\
\hline \multicolumn{4}{|l|}{ GRADING } \\
\hline G1-G2 & $22(28.2)$ & $14(35.9)$ & $8(20.5)$ \\
\hline G3 & $50(64.1)$ & $22(56.4)$ & $28(71.8)$ \\
\hline Not specified & $6(7.7)$ & $3(7.7)$ & $3(7.7)$ \\
\hline \multicolumn{4}{|l|}{ ECOG } \\
\hline 0 & $45(57.7)$ & $25(64.1)$ & $20(51.3)$ \\
\hline 1 & $28(36)$ & $13(33.3)$ & $15(38.4)$ \\
\hline 2 & $5(6.3)$ & $1(2.6)$ & $4(10.3)$ \\
\hline \multicolumn{4}{|l|}{ STAGE } \\
\hline Locally advanced & $8(10.3)$ & $3(7.7)$ & $5(12.8)$ \\
\hline Metastatic & $70(89.7)$ & $36(92.3)$ & $34(87.2)$ \\
\hline \multicolumn{4}{|l|}{$\begin{array}{l}\text { PREVIOUS ADJUVANT } \\
\text { TREATMENT }\end{array}$} \\
\hline Yes & $22(28.2)$ & $10(25.6)$ & $12(30.8)$ \\
\hline \multicolumn{4}{|l|}{ PRIMARY TUMOUR } \\
\hline Stomach & $69(88.5)$ & $34(87.2)$ & $35(89.7)$ \\
\hline Gastroesophageal junction & $9(11.5)$ & $5(14.8)$ & $4(10.3)$ \\
\hline \multirow{2}{*}{\multicolumn{4}{|c|}{$\begin{array}{c}\text { II LINE } \\
\text { CHEMOTHERAPY }\end{array}$}} \\
\hline & & & $10(25.6)$ \\
\hline \multicolumn{4}{|l|}{ USE of G-CSF } \\
\hline Yes & $16(20.5)$ & $6(15.4)$ & $10(25.6)$ \\
\hline \multicolumn{4}{|l|}{ METASTATIC SITE } \\
\hline Liver & $35(44.9)$ & $19(48.7)$ & $16(41)$ \\
\hline Lymphnodes & $37(47.4)$ & $20(51.3)$ & $17(43.6)$ \\
\hline Carcinomatosis & $14(18)$ & $7(18)$ & $7(18)$ \\
\hline Lung & $7(9)$ & $3(7.7)$ & $4(10.3)$ \\
\hline Other & $6(7.7)$ & $2(5.1)$ & $4(10.3)$ \\
\hline
\end{tabular}




\begin{tabular}{|c|c|c|c|}
\hline & Group A (\%) & Group B (\%) & $\begin{array}{c}95 \% \text { CI, } \\
\text { p }\end{array}$ \\
\hline NUMBER & $39(50)$ & $39(50)$ & \\
\hline \multicolumn{4}{|l|}{ RESPONSE } \\
\hline Complete response & $5(12.8)$ & $4(10.3)$ & \\
\hline Partial response & $20(51.3)$ & $11(28.2)$ & \\
\hline Stable disease & $7(18)$ & $12(30.8)$ & \\
\hline Progressive disease & 7 (18) & $11(28.2)$ & \\
\hline Not evaluable & $0(0)$ & $1(2.6)$ & \\
\hline Overall response rate & $25(64.1)$ & $15(38.5)$ & $\begin{array}{c}1.67-46.67 \\
0.041\end{array}$ \\
\hline $\begin{array}{c}\text { SITE OF DISEASE at ENTRY } \\
\text { with CORRESPONDING } \\
\text { TUMOUR RESPONSE }\end{array}$ & Responders/pts (\%) & Responders/pts (\%) & \\
\hline Loco-regional only & $3 / 3(100)$ & $2 / 5(40)$ & \\
\hline Distant metastases & $22 / 36(61.1)$ & $13 / 34(38.2)$ & \\
\hline
\end{tabular}




\section{Pegylated \\ doxorubicin (\%) \\ Mitomycin-C (\%)}

\begin{tabular}{ccc}
\hline NUMBER & 39 & 39 \\
\hline WHO GRADE 3+4 & & \\
NON-HAEMATOLOGICAL & & \\
TOXICITY & & $1(2.6)$ \\
Diarrhoea & $0(0)$ & $1(2.6)$ \\
Nausea/vomiting & $1(2.6)$ & $1(2.6)$ \\
Alopecia & $0(0)$ & $0(0)$ \\
Mucositis & $2(5.1)$ & $0(0)$ \\
Hand \& foot syndrome & $3(7.7)$ & $6(15.4)$ \\
Asthenia & $5(12.8)$ & $0(0)$ \\
Liver toxicity & $0(0)$ & $0(0)$ \\
Renal toxicity & $0(0)$ & $0(0)$ \\
Neurotoxicity & $0(0)$ & \\
WHO GRADE 3+4 & & $10(25.6)$ \\
HAEMATOLOGICAL & & $8(20.5)$ \\
TOXICITY & $6(15.4)$ & $0(10.3)$ \\
Neutropenia & $2(5.1)$ & $0(0)$ \\
Thrombocytopenia & $2(5.1)$ & \\
Febrile neutropenia & $0(0)$ & \\
Anemia & & \\
\hline
\end{tabular}

\section{WHO GRADE 2}

NON-HAEMATOLOGICAL TOXICITY

\begin{tabular}{ccc}
\hline Diarrhoea & $2(5.2)$ & $4(10.2)$ \\
Nausea/vomiting & $3(7.7)$ & $4(10.2)$ \\
Mucositis & $3(7.7)$ & $5(12.8)$ \\
Hand \& foot syndrome & $5(12.8)$ & $0(0)$ \\
Asthenia & $8(20.5)$ & $10(25.6)$ \\
Neurotoxicity & $4(10.2)$ & $4(10.2)$ \\
\hline WHO GRADE 2 & & \\
HAEMATOLOGICAL & & \\
TOXICITY & $6(25)$ & $6(15.4)$ \\
Neutropenia & $8(20.5)$ & $14(35.9)$ \\
Thrombocytopenia & $12(30.8)$ &
\end{tabular}


Figure 1: Time to progression of gastric cancer patients receiving liposomal doxorubicin (GROUP A - $)$ or mitomycin-C (GROUP B -----------).

Figure 2: Overall survival of gastric cancer patients receiving liposomal doxorubicin (GROUP A —) or mitomycin-C (GROUP B -----------). 